\title{
Hematology
}

\section{Association of homocysteine and inflammatory- related molecules in sickle cell anemia}

\section{Wendell Vilas-Boas, Bruno Antonio Veloso Cerqueira, Camylla V. B.} Figueiredo, Rayra Pereira Santiago, Caroline C. da Guarda, Thassila Nogueira Pitanga, Sanzio Silva Santana, Angela Maria Dias Zanette \& Marilda de Souza Goncalves

To cite this article: Wendell Vilas-Boas, Bruno Antonio Veloso Cerqueira, Camylla V. B. Figueiredo, Rayra Pereira Santiago, Caroline C. da Guarda, Thassila Nogueira Pitanga, Sanzio Silva Santana, Angela Maria Dias Zanette \& Marilda de Souza Goncalves (2015): Association of homocysteine and inflammatory-related molecules in sickle cell anemia, Hematology

To link to this article: http://dx.doi.org/10.1179/1607845415Y.0000000048

曲 Published online: 03 Sep 2015.

Submit your article to this journal $₫$

Џ Article views: 49

View related articles $\longleftarrow$

View Crossmark data \lceil 


\title{
Association of homocysteine and inflammatory-related molecules in sickle cell anemia
}

\author{
Wendell Vilas-Boas ${ }^{1 \dagger}$, Bruno Antonio Veloso Cerqueiraa, ${ }^{1,2 \dagger}$, Camylla V. B. \\ Figueiredo ${ }^{1,3}$, Rayra Pereira Santiago, ${ }^{1,3}$, Caroline C. da Guarda ${ }^{1,3}$, Thassila \\ Nogueira Pitanga ${ }^{1,3}$, Sanzio Silva Santana ${ }^{1,3}$, Angela Maria Dias Zanette ${ }^{4}$, \\ Marilda de Souza Goncalves ${ }^{1,3}$
}

\footnotetext{
${ }^{1}$ Centro de Pesquisas Gonçalo Moniz/FIOCRUZ, Salvador, Brazil, ${ }^{2}$ Universidade do Estado da Bahia, Salvador, Bahia, Brazil, ${ }^{3}$ Universidade Federal da Bahia, Salvador, Brazil, ${ }^{4}$ Fundação de Hematologia e Hemoterapia da Bahia-Hemoba, Salvador, Brazil
}

\begin{abstract}
Objective: Investigate the role of homocysteine (Hcy), Th17-related cytokines, and adhesion molecules in the inflammatory state seen in the sickle cell anemia (SCA).

Methods: We studied the Hcy, interleukin (IL)-17, and transforming growth factor $\beta$ (TGF- $\beta$ ) cytokine levels of 62 SCA patients, as well as the expression levels of inflammatory and endothelial activation markers.

Results: We found significant associations between Hcy levels and increased expression of IL-17 and TGF- $\beta$ among SCA patients, and a positive significant correlation between Hcy and soluble vascular cellular adhesion molecules (SVCAM). SCA individuals had raised IL-17 levels when compared with controls.

Discussion: These results suggest a possible role of Hyc in the induction of TGF- $\beta$ and IL-17. Other authors proposed that Hcy may contribute to the initiation and progression of vascular disease by monocyte activation, resulting in the secretion of cytokines that amplify the inflammatory response. The role of Hcy in cytokine production and oxidative stress in the endothelium may explain the increase of sVCAM expression and, the vascular activation currently described among the SCA individuals with the highest Hcy serum levels. The chronic inflammation was observed in hyperhomocysteinemic mice, with an increased expression of VCAM-1 and plasma levels of tumor necrosis factor-alpha, showing an association of this inflammatory molecule and vascular changes.

Conclusion: Our findings suggest that the increased levels of IL-17,Hcy and sVCAM contributes contributes to the vascular inflammation and activation presented by SCA patients, which probably have an important role in vaso-occlusion. On the basis of the presented data, IL-17 and Hcy might be considered as important components in the pathogenesis of SCA.
\end{abstract}

Keywords: Sickle cell anemia, Cytokines, Soluble adhesion molecules, Homocysteine, IL-17

\section{Introduction}

Sickle cell anemia (SCA) is associated with a proinflammatory state, characterized by an elevated baseline leukocyte count, known to be correlated with several specific complications and mortality of the disease, and by increased plasma levels of pro-inflammatory cytokines, such as interleukin (IL)-6 and IL-8. ${ }^{1-4}$ Inflammation, white blood cell adhesion to vascular endothelium, and consequent endothelial damage contribute to SCA pathogenesis. ${ }^{5,6}$ The chronic inflammatory state, which is different from

${ }^{\dagger}$ W.V-.B. and B.A.V.C. contributed equally to this manuscript.

Correspondence to: Marilda Souza Goncalves, Centro de Pesquisas Gonçalo Moniz/FIOCRUZ, Rua Waldemar Falcão 121, Brotas, Salvador Bahia CEP. 40.295-001, Brazil. E-mail: mari@bahia.fiocruz.br one patient to another, may partly account for the variability of the disease expression.

Intercellular adhesion molecule-1 (ICAM-1) and vascular cell adhesion molecule-1 (VCAM-1) are cytokine-inducible, single-chain glycoproteins belonging to the immunoglobulin superfamily. The ICAM-1 is constitutively expressed on vascular endothelium and cells of the immune system and is upregulated in response to various stimuli, including cytokines synthesized during inflammation. ${ }^{7,8}$

The VCAM-1 is present in activated endothelial cells after stimulation with cytokines, such as IL-1 $\beta$, tumor necrosis factor-alpha (TNF- $\alpha$ ), and IL-4. ${ }^{9,10}$ The VCAM-1 serves as a counter receptor for integrin very late activation antigen-4 ( $\alpha 4 \beta 1)$, and is important 
in the recruitment of leukocytes to inflammatory sites. ${ }^{11}$ The VCAM-1 also participates in the cellular interactions involved in lymphocyte activation, and both ICAM-1 and VCAM-1 also can be found as soluble forms circulating in plasma although the physiological roles of these soluble cell adhesion molecules are not yet clearly known. ${ }^{12-15}$

The IL-17 is a pro-inflammatory $\mathrm{T}$ cell-derived cytokine with numerous biological actions. It has been reported that IL-17 plays an essential role in microbial host protection by connecting lymphoid and myeloid host defenses. ${ }^{16}$ Although considered to be dependent on IL-23 for differentiation from naive $\mathrm{T}$ cells into Th17 cells, current work has shown that initial differentiation is dependent on transforming growth factor beta (TGF- $\beta$ ), with subsequent Th17 lineage expansion dependent on IL-23. ${ }^{17}$ The role of the Th17 response in vascular cell alterations is not well known.

The homocysteine (Hcy), a sulfur-containing amino acid, is found at low concentration in blood and cells and is an important intermediate molecule involved in the biosynthesis of methionine and cysteine. ${ }^{18}$ The high plasma concentration of Hcy is a well-established risk factor for several disorders including cardiovascular disease, stroke, venous thrombosis, and arteriosclerosis. ${ }^{19,20}$

The hyperhomocysteinemia has an important role in vascular disorders and may act through increasing cytotoxic activity, especially for endothelial cells; elevating hydrogen peroxide $\left(\mathrm{H}_{2} \mathrm{O}_{2}\right)$ levels and decreasing nitric oxide (NO) synthesis, inducing cytokine production to stimulate the inflammatory state, activation of procoagulant factors, and dysregulation of lipid metabolism via oxidative modification of low-density lipoprotein cholesterol with enhanced atherogenesis. Higher levels of Hcy have also been implicated in causing changes in the rheological properties of blood, such as decreasing antithrombin III and tissue plasminogen activator, and increasing factor VII and C-protein. ${ }^{21,22}$ Additionally, Hcy has been associated with enhanced interaction between endothelial cells and leukocytes. ${ }^{23}$

The possibility that Hcy may contribute to the ischemic phenomena present in SCA has attracted some interest in total plasma Hcy. Lowenthal et al. ${ }^{24}$ showed that the median plasma concentration of Hcy among SCA subjects was 1.5 -fold higher than that of controls. Additionally, sickle cell disease (SCD) patients have higher plasma concentrations of Hcy in spite of higher plasma folate levels and vitamin $\mathrm{B}_{12}$ concentrations compared with those observed in healthy individuals.

Since SCA patients are prone to ischemic complications, the search for mechanism is particularly challenging because the pathogenesis of vaso-occlusion involves several molecules and processes across multiple length and timescales, including polymerization and melting of hemoglobin, vascular inflammation, adhesion molecules, cytokines, and still unclear factors such as the contribution of Hcy. We hypothesized that the plasma Hcy may contribute to the increased endothelial activation and inflammatory states seen in SCA individuals, and we performed a study to assess serum concentrations of Hcy, inflammatory markers, such as IL-18, IL-23, IL-17, TGF$\beta$, and soluble adhesion molecules (sICAM and sVCAM) in SCA patients.

\section{Materials and methods}

\section{Subjects}

We studied 62 patients ( 28 men and 34 women; mean age of $21 \pm 14$ ) from Northeast, Bahia, Brazil who were diagnosed with SCA and were followed at the hematology ambulatory from the Fundação de Hematologia e Hemoterapia do estado da Bahia (HEMOBA). All patients maintained a steady-state, transfusion-free treatment course with the use of $1 \mathrm{mg}$ of oral folate supplementation. Patients had no other systemic diseases that could have potentially altered their inflammatory functions. Blood samples were obtained during regular clinical visits. The study was approved by the Fundação Oswaldo Cruz's Human Research Board and is in accordance with the Declaration of Helsinki of 1975, as revised in 2000. All subjects signed informed consent forms. Forty age-matched control individuals were included for the IL-17 analysis.

\section{Biochemical analyses of Hcy}

Serum concentrations of Hcy were measured by a chemiluminescence immunoassay using the automatic device IMMULITE 2000 (Diagnostic Products Corporation, Los Angeles, CA, USA), according to the manufacturer's instructions.

\section{Cytokine and soluble adhesion molecule measurements}

The IL-18, IL-23, IL-7, and TGF- $\beta$ serum levels were measured using Cytokine ELISA OptEIA kits (BD Pharmingen, San Diego, CA, USA) and soluble adhesion molecules (sICAM and sVCAM) were characterized using ELISA kits (R\&D Systems, Minneapolis, MN, USA), according to the manufacturer's recommendations.

\section{Statistical analysis}

Baseline characteristics were summarized as proportions and means of selected variables. The Kolmogorov-Smirnov test was performed to determine the distribution of quantitative variables. Bivariate correlation analyses were carried out to verify correlations between pairs of variables using Pearson's or Spearman's rank correlations $(r)$ and two-tailed test was used. The non-parametric 
Table 1 Steady-state hematologic markers, soluble adhesion molecules, and cytokine values of the SCA patient group

\begin{tabular}{lcc}
\hline & Mean & SD \\
\hline Hematologic markers & & \\
RBC $\left(\times 10^{6} / \mu \mathrm{l}\right)$ & 2.69 & 0.67 \\
Hemoglobin $(\mathrm{g} / \mathrm{dl})$ & 8.07 & 1.60 \\
Hematocrit $(\%)$ & 24.42 & 5.26 \\
Platelets $\left(\times 10^{3} / \mu \mathrm{l}\right)$ & 368 & 178 \\
Leukocytes $\left(10^{6} / \mathrm{ml}\right)$ & 10.9 & 3.7 \\
Reticulocytes count $(\%)$ & 6.9 & 3.1 \\
Cytokines & & \\
IL-18 $(\mathrm{pg} / \mathrm{ml})$ & 3556.81 & 1279 \\
TGF- $\beta(\mathrm{pg} / \mathrm{ml})$ & 1588.78 & 430.88 \\
IL-23(pg/ml) & 101.52 & 180.47 \\
IL-17 $(\mathrm{pg} / \mathrm{ml})$ & 3.9 & 7.8 \\
Soluble adhesion molecules & & \\
SICAM $(\mathrm{ng} / \mathrm{ml})$ & 393.37 & 95.74 \\
sVCAM $(\mathrm{ng} / \mathrm{ml})$ & 516.06 & 226.94 \\
\hline
\end{tabular}

$\mathrm{SD}$, standard deviation.

Kruskal-Wallis test was used to compare two or more groups as measured by interval variables. Test analyses were considered significant if $P$-values obtained were less than 0.05 . Data analyses were conducted using the software programs STATA 10 (StataCorp, TX, USA) and GraphPad Prism 5 (Graphpad Software, San Diego, CA, USA).

\section{Results}

Data of hematological markers, soluble adhesion molecules, and cytokine of SCA patients in steady-state are represented in Table 1.

Hcy concentration, cytokine profile, and adhesion molecules

The median of Hcy concentration in the 62 SCA patients was $7.3 \mu \mathrm{mol} / 1( \pm 3.3 \mu \mathrm{mol} / 1)$. Considering
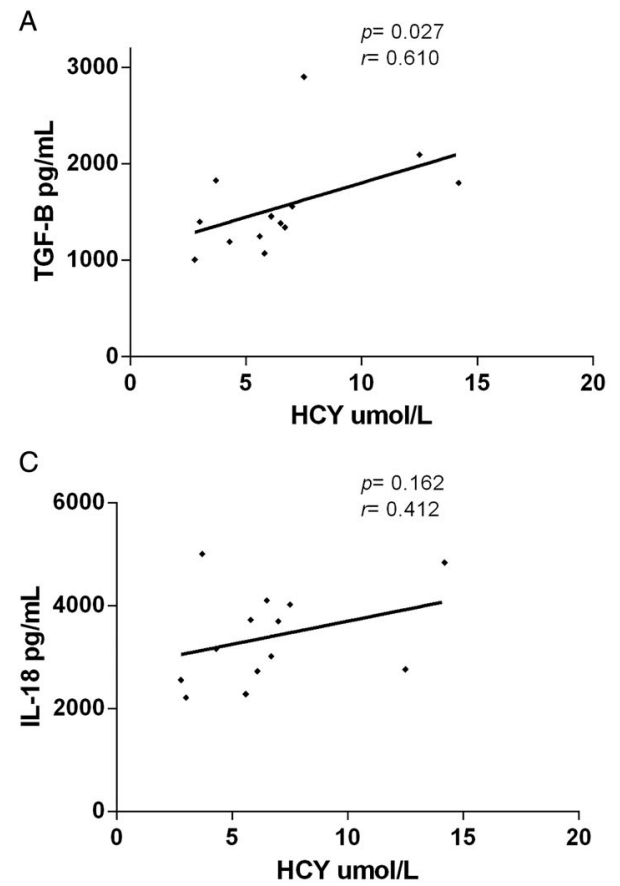

IL-17 levels are increased in SCA patient group SCA patients presented raised levels of IL-17 cytokine compared with control group $(P=0.011)$ (Fig. 4).

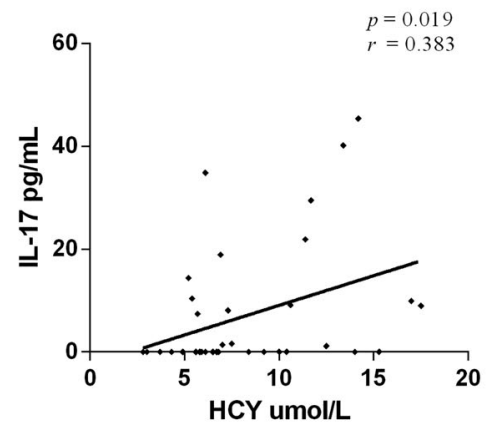

D

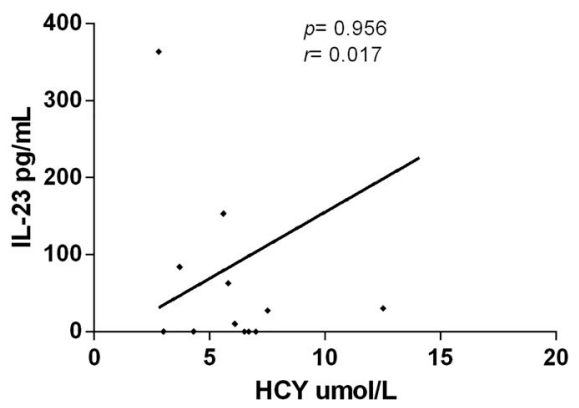

Figure 1 Hcy levels and correlation with TGF- $\beta$, IL-17, IL-18, and IL-23 cytokines in SCA patients. 

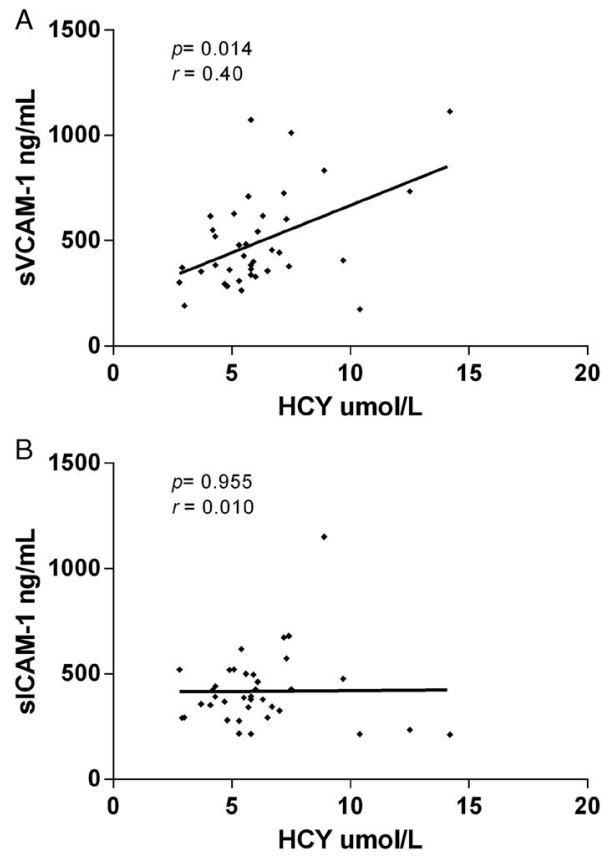

Figure 2 Hcy levels and correlation with soluble adhesion molecules in SCA patients.

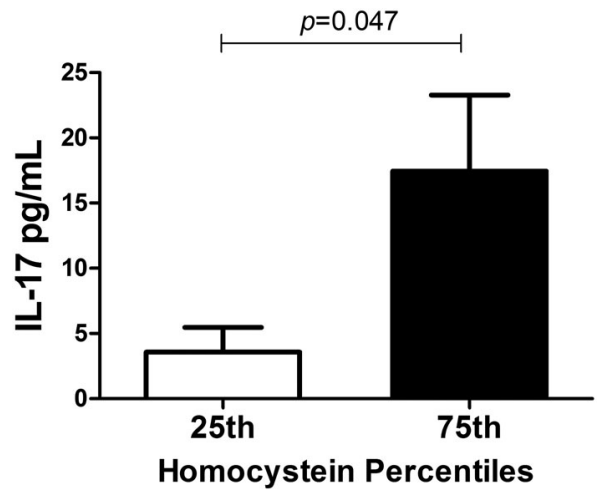

Figure 3 Hcy percentiles and levels of IL-17 in SCA individuals.

Hcy concentration, cytokines, or adhesion molecules with any clinical manifestations

We performed the analyses of Hcy, adhesion molecules, and cytokine data associated with patient's clinical profile and there were not significant results. Interestingly, we noted that one patient who had acute chest syndrome (ACS) also had high-Hcy level $(14 \mu \mathrm{mol} / 1)$ compared with mean Hcy in the group $(7.3 \mu \mathrm{mol} / 1)$.

\section{Discussion}

A chronic inflammatory state in vascular tissue is recognized to contribute to thrombotic and vasoocclusive events in SCA. Since Hcy has been associated with vascular complications in the pathology of other diseases, it may contribute to the vascular complications presented by patients with SCD. ${ }^{24}$

In our study, we investigated Hcy levels and markers of vascular activation, including cytokines and soluble

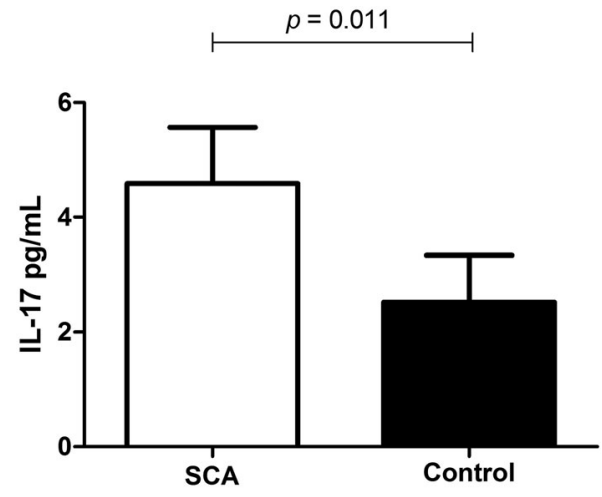

Figure 4 Levels of IL-17 in SCA individuals and controls.

adhesion molecules in SCA patients. Our results related to Hcy analyses showed that the studied group did not present increased levels of Hcy $(7.3 \mu \mathrm{mol} / 1)$ when compared with previous results from Lowenthal et al. ${ }^{24}$ that found a mean concentration of $12.6 \mu \mathrm{mol} / 1$ among SCD patients, or when compared with the common classification criterion for hyperhomocysteinemia $(>14 \mu \mathrm{mol} / \mathrm{l}){ }^{25}$ However, Balasa et al. ${ }^{26}$ found Hcy levels even lower $(5.8 \mu \mathrm{mol} / 1)$ in SCA patients and there was no difference between controls. Despite the use of folic acid by our patients, this supplementation did not influence Hcy levels, confirm previous report about no association of hyperhomocysteinemia and folic acid supplementation among SCA patients. ${ }^{27}$ In this work, We did not realize Hcy dosage in the control group to compare with Hcy levels in patients with SCA, but previous work by our team carried out a cross-sectional study comprising 143 healthy neonates, from the same population, that showed Hcy mean levels about $7.4 \mu \mathrm{mol} / 1$ in this group, showing that in the SCA group investigates, the Hcy levels were not elevated when compared with individuals from the same population. ${ }^{28}$

The effect of Hcy on cytokine production is not well understood. We found a positive association among Hcy and IL-17 and TGF- $\beta$. The IL-17 promotes inflammation by induction of various pro-inflammatory cytokines and chemokines, recruitment of neutrophils, enhancement of antibody production, and activation of $\mathrm{T}$ cells. ${ }^{29}$ The TGF- $\beta$ is a pleiotropic cytokine involved in several human diseases, including cardiovascular disease, and also can induce IL-17 production. ${ }^{30}$ Our results suggest a possible role of Hcy in the induction of TGF- $\beta$ and IL-17. This hypothesis is supported by $\mathrm{Su}$ et al. ${ }^{31}$ who proposed that Hcy may contribute to the initiation and progression of vascular disease by monocyte activation, resulting in the secretion of cytokines that amplify the inflammatory response. We also found an elevated basal level of IL-17 in SCA patients when compared with controls, representing the chronic inflammatory state in these individuals. 
A new field of research in SCA is rising on Th17 cells. These IL-17 producing cells are involved in the inflammatory response and a little information is available regarding studies in SCA. Thus, it becomes important to investigate the role of cytokines in endothelial dysfunction and activation, once the role of other molecules, such as IL-1 and TNF- $\alpha$, is yet not very established. Our team has previously demonstrated a significant and positive association of TGF- $\beta$ and circulating arginase levels in SCA patients, showing a vascular relevance of this cytokine and the need to clarify the role of these molecules in SCA. ${ }^{32}$

We found lower levels of IL-17 and TGF- $\beta$ in this study when compared with previous reports. ${ }^{21,22}$ These discrepancies can be due to genetic differences in the studied populations. More importantly, the IL-17 control group in this work is age-matched and from the same population as the SCA patients. Many patients and controls had undetectable IL17, so levels of this cytokine appear to be usually very low.

We believe that the role of Hcy in cytokine production and oxidative stress in the endothelium may explain our findings related to the increase of sVCAM expression and, consequently, with the vascular activation currently described among the SCA individuals with the highest Hcy serum levels. In agreement with our results, Hofmann et al. ${ }^{33}$ observed evidence of chronic inflammation in hyperhomocysteinemic mice, including an increased expression of VCAM-1 and elevated plasma levels of TNF- $\alpha$, showing an association of this inflammatory molecule and vascular changes. Hcy could be considered an emerging potential target of inflammation in SCA and it may be significant in the investigation of vasoocclusion. The ACS is a combination of radiographic evidence of new pulmonary infiltrates and respiratory symptoms, and is a frequent cause of hospitalization in SCA, also, it likely involves alterations of normal homeostatic functions of vascular endothelium in the lungs. ${ }^{34} \mathrm{We}$ did not find other studies that related to our finding of increased Hcy in ACS, indicating the importance of further investigation of this potential link.

We conclude that the combination of IL-17, Hcy, and sVCAM may be involved in vascular damage in SCA and this might be implicated in the disease pathogenesis. Additional studies including SCA patients under vaso-occlusive crises are warranted in order to confirm our findings and show the behavior of these molecules in crisis condition. More importantly, we suggest the development of a longitudinal study in order to answer more accurately the influence of these molecules on vascular damage in SCA.

\section{Acknowledgments}

We thank the patients for their participation because without them, this study would not have been conducted.

\section{Disclaimer statements}

Contributors W.V-.B. is graduated in Biological Sciences from the Universidade Federal da Bahia (UFBA) and $\mathrm{PhD}$ in Experimental Human Pathology of the Centro de Pesquisas Gonçalo Moniz (CPqGM). B.C. is graduated in Biochemistry Pharmacy from UFBA and $\mathrm{PhD}$ in Experimental Human Pathology of the CPqGM. A.Z. is graduated in Medicine from the Universidade Federal do Rio Grande do Sul, and she is currently the Medical Hematologist of HEMOBA. C.F. is Pharmacy undergraduate student at the UFBA. R.S. is graduated in Biological Sciences from UFBA and currently is Master's student in Experimental Human Pathology of the CPqGM. C.G. is graduated in Biomedicine from Universidade Estadual de Santa Cruz (UESC) and currently is Master's student in Experimental Human Pathology of the CPqGM. T.P. is graduated in Pharmacy from UFBA and $\mathrm{PhD}$ student in Experimental Human Pathology of the CPqGM. S.S. is graduated in Biomedicine from UESC and $\mathrm{PhD}$ student in Experimental Human Pathology of the CPqGM. M.G. is graduated in Biochemistry Pharmacy from UFBA and $\mathrm{PhD}$ at Genetics from Universidade Estadual de Campinas, and she is currently titular researcher of $\mathrm{CPqGM}$ and professor in the Faculdade de Farmácia da Universidade Federal da Bahia.

Funding This work was supported by grants from the Conselho Nacional de Desenvolvimento Científico e Tecnológico (CNPq) (311888/2013-5, 478755/20090 , and 07496/2010-4) (M.S.G.); the Fundação de Amparo à Pesquisa do Estado da Bahia (FAPESB) (1431040053063 and 9073/2007) (M.S.G.); MCD/CNPq/MS-SCTIE-DECIT (409800/2006-6), (M.S.G.). The sponsors of this study are public or nonprofit organizations that support general science research. They had no role in gathering, analyzing, or interpreting the data.

Conflicts of interest The authors stated that there are no conflicts of interest regarding the publication of this article.

Ethics approval The study was approved by the Fundação Oswaldo Cruz's Human Research Board and is in accordance with the Declaration of Helsinki of 1975, as revised in 2000. All subjects signed informed consent forms.

\section{References}

1 Platt OS, Brambilla DJ, Rosse WF, Milner PF, Castro O, Steinberg $\mathrm{MH}$, et al. Mortality in sickle cell disease. Life 
expectancy and risk factors for early death. N Engl J Med. 1994; 330:1639-44.

2 Balkaran B, Char G, Morris JS, Thomas PW, Serjeant BE, Serjeant GR. Stroke in a cohort of patients with homozygous sickle cell disease. J Pediatr. 1992;120:360-6.

3 Duits A, Schnog JB, Lard LR, Saleh AW, Rojer RA. Elevated IL-8 levels during sickle cell crisis. Eur J Haematol. 1998;61: $302-5$.

4 Etienne-Julan M, Belloy MS, Decastel M, Dougaparsad S, Ravion S, Hardy-Dessources MD. Childhood sickle cell crises: clinical severity, inflammatory markers and the role of interleukin-8. Haematology 2004;89:863-4.

5 Platt OS. Sickle cell anemia as an inflammatory disease. J Clin Invest. 2000;106:337-8.

6 Kaul DK, Hebbel RP. Hypoxia/reoxygenation causes inflammatory response in transgenic sickle mice but not in normal mice. J Clin Invest. 2000;106:411-20.

7 Dustin ML, Rothlein R, Bhan AK, Dinarello CA, Springer TA. Induction by IL-1 and interferon-g: tissue distribution, biochemistry, and function of a natural adherence molecule (ICAM-1). J Immunol. 1986;137:245-54. J Immunol. 2011;186:137-245.

8 Rothlein R, Dustin ML, Marlin SD, Springer TA. A human intercellular adhesion molecule (ICAM-1) distinct from LFA-1. J Immunol. 2011;186:5024-33.

9 Osborn L, Hession C, Tizard R, Vassallo C, Luhowskyj S, ChiRosso G, et al. Direct expression cloning of vascular cell adhesion molecule 1, a cytokine-induced endothelial protein that binds to lymphocytes. Cell 1989;59:1203-11.

10 Rice GE, Bevilacqua MP. An inducible endothelial cell surface glycoprotein mediates melanoma adhesion. Science 1989;246: 1303-06.

11 Elices MJ, Osborn L, Takada Y, Crouse C, Luhowskyj S, Hemler ME, et al. VCAM-1 on activated endothelium interacts with the leukocyte integrin VLA-4 at a site distinct from the VLA-4/fibronectin binding site. Cell 1990;60:577-84.

12 Postigo AA, Garcia-Vicuna R, Diaz-Gonzalez F, Arroyo AG, De Landázuri MO, Chi-Rosso G, et al. Increased binding of synovial $\mathrm{T}$ lymphocytes from rheumatoid arthritis to endothelial-leukocyte adhesion molecule-1 (ELAM-1) and vascular cell adhesion molecule-1 (VCAM-1), J Clin Invest. 1992;89: $1445-52$.

13 Van Seventer GA, Newman W, Shimizu Y, Nutman TB, Tanaka $\mathrm{Y}$, Horgan KJ, et al. Analysis of T cell stimulation by superantigen plus major histocompatibility complex class II molecules or by $\mathrm{CD} 3$ monoclonal antibody: costimulation by purified adhesion ligands, VCAM-1, ICAM-1, but not ELAM-1. J Exp Med. 1991;174:901-13.

14 Seth R, Raymond FD, Makgoba MW. Circulating ICAM-1 isoforms: diagnostic prospects for inflammatory and immune disorders. Lancet 1991;338:83-4.

15 Gearing AJH, Hemingway I, Pigott R, Hughes J, Rees AJ, Cashman SJ. Soluble forms of vascular adhesion molecules, Eselectin, ICAM-1 and VCAM-1: pathological significance. Ann NY Acad Sci. 1992;667:324-31.

16 Schwarzenberger P, Kolls JK. Interleukin 17: an example for gene therapy as a tool to study cytokine mediated regulation of hematopoiesis. J Cell Biochem. 2002;38:88-95.

17 Stockinger B, Veldhoen M. Differentiation and function of Th17 cells. Curr Opin Immunol. 2007;19:281-6.
18 Bialecka M, Robowski P, Honczarenko K, Roszmann A, Sławek J. Genetic and environmental factors for hyperhomocysteinaemia and its clinical implications in Parkinson's disease. Neurol Neurochir Pol. 2009;43:272-85.

19 Refsum H, Ueland PM, Nygard O, Vollset SE. Homocysteine and cardiovascular disease. Annu Rev Med. 1998;49:31-62.

20 Clarke R, Daly L, Robinson K, Naughten E, Cahalane S, Fowler B, et al. Hyperhomocysteinemia: an independent risk factor for vascular disease. N Eng J Med. 1991;334:1149-55.

21 Siniscalchi A, Mancuso F, Gallelli L, Ibbadu GF, Mercuri NB, De Sarro G. Increase in plasma homocysteine levels induced by drug treatments in neurologic patients. Pharmacol Res. 2005;52:367-75.

22 Postuma RB, Lang AE. Homocysteine and levodopa: should Parkinson disease patients receive preventative therapy? Neurology 2004;63:886-91.

23 Dudman NP, Temple SE, Guo XW, Fu W, Perry MA. Homocysteine enhances neutrophil-endothelial interactions in both cultured human cells and rats in vivo. Circ Res. 1999;84: $409-16$.

24 Lowenthal EA, Mayo MS, Cornwell PE, Thornley-Brown D. Homocysteine elevation in sickle cell disease. J Am Coll Nutr. 2000;19:608-12.

25 Hansrani M, Gillespie JI, Stansby G. Homocysteine in myointimal hyperplasia. Eur J Vasc Endovasc Surg. 2002;23:3-10.

26 Balasa VV, Gruppo RA, Gartside PS, Kalinyak KA. Correlation of the C677T MTHFR genotype with homocysteine levels in children with sickle cell disease. J Pediatr Hematol Oncol. 1999;21:397-400.

27 Dhar M, Bellevue R, Brar S, Carmel R. Mild hyperhomocysteinemia in adult patients with sickle cell disease: a common finding unrelated to folate and cobalamin status. Am J Hematol. 2004; 76:114-20.

28 Couto FD, Moreira LM, Dos Santos DB, Reis MG, Gonçalves MS. Folate, vitamin B12 and total homocysteine levels in neonates from Brazil. Eur J Clin Nutr. 2007;61:382-86.

29 Iwakura I, Nakae S, Saijo S, Ishigame H. The roles of IL-17A in inflammatory immune responses and host defense against pathogens. Immunol Rev. 2008;226:57-79.

30 Rodríguez-Vita J, Sánchez-Galán E, Santamaría B, SánchezLópez E, Rodrigues-Díez R, Blanco-Colio LM, et al. Essential role of TGF-beta/Smad pathway on statin dependent vascular smooth muscle cell regulation. PLoS One 2008;3:3959.

31 Su SJ, Huang LW, Pai LS, Liu HW, Chang KL. Homocysteine at pathophysiologic concentrations activates human monocyte and induces cytokine expression and inhibits macrophage migration inhibitory factor expression. Nutrition 2005;21:994-1002.

32 Vilas-Boas W, Cerqueira BA, Zanette AM, Reis MG, BarralNetto M, Goncalves MS. Arginase levels and their association with Th17-related cytokines, soluble adhesion molecules (sICAM-1 and sVCAM-1) and hemolysis markers among steady-state sickle cell anemia patients. Ann Hematol. 2010;89: 877-82.

33 Hofmann MA, Lalla E, Lu Y, Gleason MR, Wolf BM, Tanji N, et al. Hyperhomocysteinemia enhances vascular inflammation and accelerates atherosclerosis in a murine model. J Clin Invest. 2001:107:675-83.

34 Paul RN, Castro OL, Aggarwal A, Oneal PA. Acute chest syndrome: sickle cell disease. Eur J Haematol. 2011;87:191-207. 